\title{
The Application of Sky Quality Meter at Twilight for Islamic Prayer Time
}

\author{
Nur Nafhatun Md Shariff, Amran Muhammad, Mohd Zambri Zainuddin, and Zety Sharizat Hamidi
}

\begin{abstract}
The aim of this study is to detect elusive light that indicate the prayer time (Isha'). Therefore, we focused on optical sky brightness at dusk from May 2007 through April 2008 intermittently. The measurements of twilight sky brightness were covered at one (1) site covering; West coast of Peninsular Malaysia. The measurements were done by applying Sky Quality Meter (SQM) which covered between 400-700 $\mathrm{nm}$ in accordance of human eyes and SQM range. Results showed that there are clear indications of light changes when Sun at certain degree below horizon that visible by plateau form in twilight sky brightness dependences versus solar zenith angle. It is clarified that the yearly averages of solar depression by observation are best correlated within the range of $17.30-19.50$ for Isha'.
\end{abstract}

Index Terms-Twilight; prayer time; sky quality meter.

\section{INTRODUCTION}

Early studies done by astronomers such as Ibn Muadh, al-Biruni, al-Qayini, Ibn Yunus etc.[1], [2]. Ibn al-Shạtir adopted various value for each prayer times such as $17^{\circ}$ for Isha' due to their asymmetry property [3]. There are many efforts made on sky twilight measurement using a photometer and a CCD camera, yet they are not specific on prayer times determination [4]- [6]. In this paper, we show that elusive light can be detected i.e. shafaq alabyad [7]. The elusive light is detected when Sun dip below horizon. The important of knowing angle of elusive light solely for determination of two prayer times i.e. Isha' and Subh. Based on that, we investigated Isha' prayer time using Sky Quality Meter (SQM).

\section{INSTRUMENT PERFORMANCE}

In order to understand the measurements, it was tested and characterized by checking the acceptance angle, linearity and spectral responsivity [8] by running photoelectric effects experiments[7]. A trough is formed on the graph as evidence of SQM characteristic to behave when certain colours (wavelength) strike on its sensor. Both values have a high correlation and clearly when twilight colours (lower wavelength colours) hit the sensor, it consistently gives high readings - see Fig. 1. The

Manuscript received March 9, 2012; revised April 20, 2012.

Nur Nafhatun Md Shariff, Amran Muhammad, and Mohd Zambri Zainuddin are with Faculty of Science, University of Malaya (UM) (email: nur.nafhatun.ms@gmail.com).

Zety Sharizat Hamidi is with Faculty of Applied Science, MARA University of Technology (UiTM) obtained response curve of SQM multiplying the spectral responsivity of the TAOS TSL237 photodiode by the transmittance of the Hoya CM-500 filter.

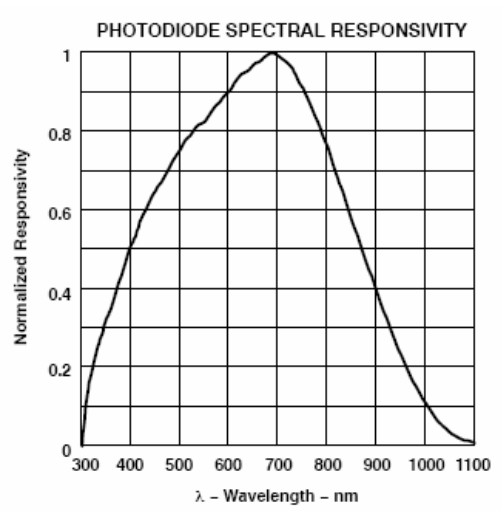

Fig. 1. Spectral response of SQM.

\section{EXPERIMENTAL PROCEDURES}

The brightness of twilight sky observations were carried out from May 2007 until April 2008 intermittently in accordance of photometric night. We choose one (1) site in Malaysia with certain qualities, i) best obstructionfree horizon and ii) the least light-pollution surrounding. It was carried out in the city peripheral Port Klang (Selangor). We took appropriate measure for every phase i.e. pre-observation, observation and post-observation [7]. The measurements were covered between $400-700 \mathrm{~nm}$ in accordance of human eyes and SQM range. Data were taken in two minutes interval.

\section{RESUlt AND Discussion}

For Isha', receipt of light is measured in terms of increase in magnitude values (decreasing of light) and fluctuate between $17 \cdot 3^{\circ}-19.5^{\circ}$. By plotting the magnitude values against time, a characteristic growth curve can be observed. The curve is divided into three (3) phases. The first phase is slow growth which means there was still bright light even the Sun just set. In the second phase shows a minimum of two gradual acclivities is increase at the certain rate. The gradual acclivity demonstrates receipt of light when the Sun is at certain degrees below horizon $\left(6^{\circ}\right.$ and $\left.12^{\circ}\right)$. The third stage is the stationary phase when growth stops and no increase in magnitude values for a period of time and this prove the beginning of Isha' is indicated by a formed plateau - see Fig. 2 as interpreted from Table I. 
TABLE I: LIGHT DETECTION OF ISHA’ AT PORT KLANG, 5 APRIL 2008

\begin{tabular}{ccc}
\hline Time & SQM & Altitude of Sun \\
\hline $19: 10$ & 8.22 & 2.461 \\
$19: 12$ & 8.55 & 1.978 \\
$19: 14$ & 8.73 & 1.495 \\
$19: 18$ & 9.12 & 1.012 \\
$19: 22$ & 9.69 & 0.529 \\
$19: 24$ & 9.98 & 0.046 \\
$19: 26$ & 10.47 & -0.956 \\
$19: 28$ & 10.48 & -1.456 \\
$19: 30$ & 11.24 & -1.955 \\
$19: 32$ & 11.73 & -2.454 \\
$19: 34$ & 12.21 & -3.753 \\
$19: 36$ & 12.65 & -4.786 \\
$19: 38$ & 12.76 & -5.752 \\
$19: 40$ & 14.55 & -6.236 \\
$19: 44$ & 15.44 & -6.789 \\
$19: 46$ & 15.81 & -7.686 \\
$19: 48$ & 16.25 & -8.169 \\
$19: 50$ & 16.66 & -8.653 \\
$19: 52$ & 17.23 & -9.136 \\
$19: 56$ & 17.96 & -9.619 \\
$19: 58$ & 17.99 & -10.586 \\
$20: 00$ & 18.23 & -11.553 \\
$20: 02$ & 18.46 & -12.553 \\
$20: 04$ & 18.55 & -13.003 \\
& &
\end{tabular}

\begin{tabular}{ccc}
$20: 06$ & 18.69 & -13.487 \\
$20: 08$ & 18.95 & -13.97 \\
$20: 10$ & 19.11 & -14.454 \\
2012 & 19.12 & -14.938 \\
$20: 14$ & 19.13 & -15.422 \\
$20: 16$ & 19.13 & -15.906 \\
$20: 18$ & 19.23 & -16.39 \\
$20: 20$ & 19.5 & -16.874 \\
$20: 22$ & 19.48 & -17.358 \\
$20: 24$ & 19.36 & -17.842 \\
$20: 26$ & 20.32 & -17.927 \\
$20: 28$ & 20.33 & -18.326 \\
$20: 32$ & 20.32 & -18.81 \\
$20: 34$ & 20.3 & -19.03 \\
$20: 36$ & 20.28 & -19.294 \\
$20: 38$ & 20.23 & -19.778 \\
$20: 40$ & 20.22 & -20.262 \\
$20: 44$ & 20.23 & -20.746 \\
$20: 46$ & 20.21 & -21.23 \\
$20: 48$ & 20.23 & -21.714 \\
$20: 52$ & 20.24 & -22.682 \\
$20: 54$ & 20.22 & -23.166 \\
$20: 56$ & 20.23 & -23.65 \\
$20: 58$ & 20.21 & -24.134 \\
$21: 00$ & 20.2 & -25.393 \\
\hline & &
\end{tabular}

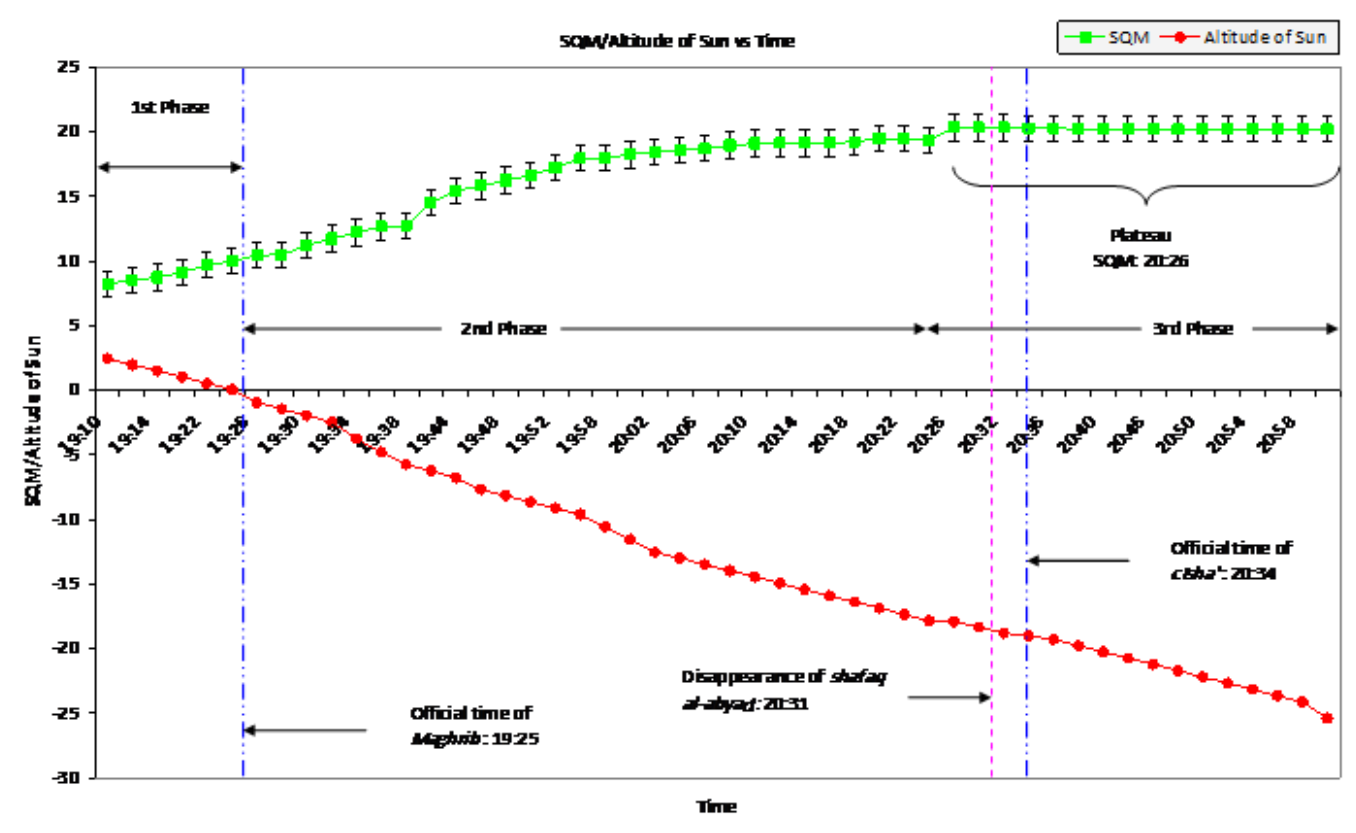

Fig. 2. Ligh de ec io of sh' Po K g, 5 Ap i 2008

V. CONCLUSION

From the evidence, SQM is able to assist the process of determining the beginning of Isha'. It is plausible that the value of twilight angle is fluctuating between for Isha' according what is given by the instrument.

\section{ACKNOWLEDGEMENT}

The authors wish to thank IPPP of University of Malaya for financial assistance.

\section{REFERENCES}

[1] D. A. King. Call of the Muezzin: (Studies I-IX). E. J. Brill, 2004. 
[2] D. A. King, In Synchrony with the Heavens, Studies in Astronomical Timekeeping and Instrumentation in Medieval Islamic Civilization, vol. 2, E. J. Brill, 2005.

[3] B. R. Goldstein, Theory and Observation in Ancient and Medieval Astronomy, Variorum, 1985.

[4] M. W. Chiplonkar and P. V. L. Kulkarni, "Seasonal Variation of Twilight Intensity," Czechoslovak Academy of Science, 10, 1959.

[5] O. S. Ugolnikov, "O. V. Postylyakov and I. A. Maslov, "Effects of Multiple Scattering and Atmospheric Aerosol on the Polarization of the Twilight," Journal of Quantitative Spectroscopy \& Radiative transfer, pp. 88, 2004.
[6] N. D. Tyson and R. R. Gal, "An Exposure Guide for Taking Twilight Flatfields with Large Format CCDs," The Astronomical Journal, vol.105, no. 3, 1993.

[7] N. N. M. Shariff, Sky Brightness at Twilight: Detectors Comparison between Human Eyes and Electronic Device for Isha' and Subh from Islamic and Astronomical Considerations, in Science and Technology Studies, University of Malaya: Kuala Lumpur. 2008.

[8] P. Cinzano, Night Sky Photometry with Sky Quality Meter, in ISTIL Internal Report., ISTIL (Instituto di Scienza e Tecnologia dell'Inquinamento Luminoso), Italy, 2005. 